\title{
Revolution and Ideology
}

\author{
Truth, Lies, and Mediation
}

\begin{abstract}
Morality, religion, metaphysics, all the rest of ideology and their corresponding forms of consciousness, thus no longer retain the semblance of independence. They have no history, no development; but men, developing their material production and their material intercourse, alter, along with this their real existence, their thinking and the products of their thinking.

-KARL MARX
\end{abstract}

Consider how poet Octavio Paz describes the Mexican Revolution: "A search for our own selves ... a releasing of many ferocious, tender and noble feelings that had been hidden by our fear of being" (Paz [1950] 2005: 149). ${ }^{1}$ In Paz's words the revolution features as an instance of unprecedented authenticity, one finally offering Mexicans the opportunity to express their real emotions, aspirations, and desires. An "explosion of reality" (149), Paz calls it. Such words resonate with many other descriptions of the revolutionary moment. Take, for instance, Franz Fanon's famous account of the Algerian anticolonial revolution of the 1950s. "After centuries of unreality, after having wallowed in the most outlandish phantoms, at long last the native, gun in hand, stands face to face with the only forces which contend for his life-the forces of colonialism" (Fanon [1961] 2007: 58). Revolution, in these descriptions, is understood not only as the beginning of a new state of affairs, ushering in the New Man of chapter 3, but also as the end of "unreality." This is the moment in which illusions and phantoms come to an end, and the reality of self and things can at last emerge; a time when, in the words of Chairman Mao, one can "grasp the essence of the thing" (Tse Tung [1930] 2014: 119), meet the truth face to face, and distinguish, gun in hand, between friends and foes, verity and lies, real and unreal.

1. The Mexican Revolution, also referred to as the Mexican Civil War, represents a lengthy process of political change that began a century after the Hidalgo insurrection discussed in chapter 1. 
Revolutions, it seems, bring about disclosure. Reality, once hidden, is made manifest. To describe this process, both theoreticians and practitioners of revolution have often made use of a specific concept, a notion that has featured in the speeches and writings of countless agitators, radicals, and rebels: ideology. This loaded term appears in a variety of discourses, at times simply indicating systems of ideas that are shared by a group of people, often with reference to political creeds, but also, more broadly, to interpretations of the way society works and explanations of what it means to be human. Ideologies, in this understanding, are descriptions of reality that help us make sense of the world (Geertz 1973b: 220; Therborn 1999: 2). Further, even though this use of the term does not prevent judgments on which ideologies describe the real accurately and which do not, here the concept itself holds a neutral connotation (Mannheim [1936] 2000: 59-83; Abercrombie et al. [1980] 2014: 188). There might be good and bad ideologies but, ultimately, the term "ideology" simply designates a worldview. There is, however, another use of the word, one that requires us to take a much stronger stance in assessing the way reality is described, and it is this second, more intense meaning of the concept that historically has proved more influential in revolutionary discourses.

One can detect traces of this stronger connotation even when "ideology" is used in a nonevaluative manner. Even when one deploys the concept simply to mean "the way in which a group sees reality," the term always has certain implications. Ideologies are culturally specific in that they always interpret reality through the lenses of social, political, or religious views; consequently, they are not impartial (Therborn 1999: 3). Indeed, they are emotive, tending to describe the world as one would like it to be, rather than as it is (Geertz 1973b: 205). Ideologies, therefore, are usually seen as discourses that differ, whether in style or content, from supposedly objective descriptions of the real produced in disciplines such as economics or the natural sciences, although it is understood that these too might entail ideological views (Abercrombie et al. [1980] 2014: 173-74). ${ }^{2}$ Indeed, this notion of ideology as subjective discourse can be found even when philosophers use the concept to claim that the world begins to exist only when we describe it, and that, therefore, there is no such thing as an objective reality devoid of ideological connotations. In this case too there is an implication that our descriptions of the world inevitably carry with them our prejudices and preferences (Jameson 1984: viii; Anderson 1998: 24).

Now, this view of ideology as partial and ultimately tendentious description of the real has a precise genealogy. It is with Marx that the concept first acquires

2. "Where science is the diagnostic, the critical, dimension of culture, ideology is the justificatory, the apologetic one" (Geertz 1973b: 231). "Not all ideology is or can operate as science, art, philosophy, or law, but all these emerge out of ideological configurations and may function as ideologies" (Therborn 1999: 2). 
the meaning of a biased, not completely truthful interpretation of things, and it is due to him that the term has become forever part of the revolutionary vocabulary (Therborn 1999: 4). Ideology, in the Marxist framework, indicates false beliefs that in time have become a habitual component of the way we interpret the world. These sedimented lies, for Marx, can be challenged and uprooted by revolutionary effort, and it is often in this sense that the revolution is understood as an event that reveals reality. Revolution puts an end to ideology and, when this happens, Marx tells us, false descriptions of reality are replaced with new, more reliable interpretations that are closer to the actual truth of life and society. These views-and the opposition between ideology and reality that they imply-have been developed by various Marxist philosophers, and in this chapter we briefly present some of the main theories produced in this context by these thinkers. However, we also juxtapose these reflections with the way notions of truthfulness and falseness are articulated, thought about, and put into practice in concrete revolutionary contexts.

As we will see, in places like Iran and Libya, revolution has certainly been understood as an event that establishes a more truthful existence. Some of these revolutionary discourses have also been influenced in various degrees by Marxist views. Nevertheless, we will see that these contexts have produced their own understandings of what counts as real and what counts as ideological, and these notions have often been articulated in ways that are different from those of the European revolutionary tradition. Exploring these local takes on the relationship between reality and ideology gives us a chance to tackle a number of questions. If ideologies are false representations of the real, then why do people believe them to be true; furthermore, do they actually believe in them at all? Is it possible, as Marx thought, to end ideology? Is revolution necessarily about extinguishing anything that stands between us and reality? Proponents of Marxist lore have provided insightful answers to some of these queries, but so have Iranian ayatollahs and Bolivian social movements. Let us therefore see how these answers resemble or differ from each other, mapping how different revolutionaries have positioned themselves vis-à-vis the complex relationship that exists between reality and the way we describe it.

\section{THE WORLD UPSIDE DOWN}

To better compare Marxist thought with other revolutionary discourses we first need to explain how, according to Marx, ideology is false. To this end it is useful to clarify that before Marx, in the aftermath of the French Revolution, liberal philosopher Antoine Destutt de Tracy had already used the term ideology, and Marx knew it. In the context of the celebration of reason that marked the Enlightenment, Tracy had proposed the creation of a new science of ideas, a discipline that would study mental processes using the means of natural sciences (Rich- 
ards 1993: 103). Tracy called this discipline "ideology," and claimed that his new science could objectively assess which of the ideas put forward by the French Revolution were sound and which were not. This was, for Tracy, a way to purify the revolution of its irrational and utopic components, which he located in the demands for redistribution of wealth and direct democracy that had been made by revolutionary groups close to the sans-culottes (Rehmann 2013: 18). In opposing these requests Tracy enlisted ideas whose reliability was supposedly proven by the science of ideology, namely the need for people to be governed by representatives, and the individual's right to do as he pleases with his property (Tracy [1818] 1973: 47).

Interestingly, Marx too believed that ideology provided a justification for these ideas, although he understood this dynamic in a completely different way. Tracy had attempted to prove that liberal values were scientifically truthful, rational, and rooted in human nature (Tracy [1818] 1973: 23). Marx, on the contrary, did not see these values as objectively true, but rather as the product of Tracy's subjective way of seeing the world: an expression of his background and of the social class to which he belonged. In particular, according to Marx, Tracy's defense of private property had mainly to do with the fact that, apart from being a philosopher, Tracy was a wealthy landowner and "a fish-blooded bourgeois doctrinaire" (Marx [1867] 2011: 711), and, as such, he was inclined to protect his property against the demands of the unprivileged. Tracy's ideology was thus a convenient subjective truth presented as the truth, and the same applied, in Marx's view, to other ideas in the domain of politics, law, and morality. In all that "men say, imagine, conceive" (Marx and Engels 2001: 47), Marx thought, there is ideology: ideas that are presented as natural and good for all, while in fact they serve the interests of the few. ${ }^{3}$

Thus, for Marx ideology has a dangerous capacity for deceit, particularly in the context of capitalism. Ideological discourses justify the divide between those who own the property, capital, and means to produce and sell, and those who, in order to survive, are forced to work for and buy from the former. Ideology deceives by hiding the exploitative character of this divide, and, therefore, by representing reality in a completely twisted manner. In ideology "men and their circumstances appear upside down" (Marx and Engels 2001: 47), and this distorting quality, Marx argued, is so powerful that it infects the very consciousness of people. Religion, for Marx, played an important role in this process. By confining the realization of justice to the afterlife, religious discourses justify exploitation in this life, contributing to the creation of a "false consciousness" in the oppressed (Engels 1942a: 511): an

3. Napoleon was the first to use ideology in a pejorative sense. Tracy's followers were known as idéologues, a term that came to indicate thinkers influenced by the Enlightenment. Napoleon accused them of undermining his authority, dismissed their science, and declared, "we must lay the blame for the ills that our fair France has suffered on ideology" (Rehmann 2013: 19). 
illusionary image of the self based on the idea that it is natural for the poor to live a life of sacrifice working for a master without enjoying the fruits of their own labor because such is God's will (Marx 2007: 72).

In Marxist thought there is, therefore, a clear-cut division between ideology and reality. On the one hand, there is the real, the tangible actuality of exploitation; on the other, there is the unreal, "the chimeras, the ideas, dogmas" (Marx and Engels 2001: 37), the ephemeral falsities of ideology. In this differentiation, for Marx, lies the key to instigating revolutionary change. By looking at the concrete inequality that exists in society, one discovers that what appears good in ideology is bad in reality, thus uncovering the contradictions of ideology "in a purely empirical way" (42). This realization brings about another. Although ideology affects people's lives, it is not, strictly speaking, a real thing that exists in itself. Ideology only exists in our heads; it is made of inconsistent concepts and thoughts that are there only to justify the reality of exploitation. ${ }^{4}$ As such, ideology will vanish as soon as exploitative conditions come to an end (47). When revolution establishes fairer material conditions - a better reality for all-humans will abandon false consciousness, and embrace their real selves, the "essence of men" (37), which, for Marx, entails the capacity to satisfy one's needs by creatively expressing oneself through work. ${ }^{5}$

Marx's revolutionary project had a universal vocation. The emancipation of the oppressed, in his view, would bring about the emancipation of all humans: the end of the tyranny of lies and a return to reality and truth for all mankind (Marx 1970: 140-41). This appealing promise attracted the interest of many, with Marx's premises offering themselves to a variety of readings. Marx himself elaborated some of his views during his lifetime and left much unsaid, leaving space for different interpretations of whether ideology could be considered to be completely false (Eagleton 1991: 87). This allowed Marxist philosophers to interrogate Marx's sharp differentiation between reality and ideology, and to theorize the possibility that there might be points of contact between the two. In particular, these intellectuals became interested in the gray area that might exist between the real and the unreal, and in the possibility that the unreal lies of ideology might paradoxically prove useful in establishing the reality of revolution. Therefore, before we look at how these issues have been dealt with in other revolutionary contexts, it is worth examining how Marxist thinkers have tried to stay within the parameters of Marxism

4. According to the majority of commentators, Marx thought that while it is true that ideology is generated by material conditions, it is also true that in turn it influences these conditions. This position is clearly stated by Engels (1942b: 475).

5. On the one hand, Marx thought that specific material conditions create specific ideological stances on what it means to be human (Marx and Engels 2001: 47). On the other hand, Marx believed that the ability to freely and consciously transform the world through work is an inherently human characteristic, our "species being" (Marx 1974: 329; Wartenberg 1982: 79-80; Patterson 2009: 39-57). 
and, at the same time, go beyond it. Many have debated these matters, but here we consider only a few examples of theoreticians who have examined the degree to which the unreal can be real.

\section{THE REALITY OF IDEOLOGY}

One of the first to embark on such an endeavor was Italian intellectual Antonio Gramsci, whose influential ideas can help us chart the different approaches to ideology that developed after Marx. Gramsci brought about a fundamental innovation in Marxism, introducing the idea that for ideology to work as a tool of power the oppressed must give their consent to it. To elucidate this point, Gramsci identified a specific component of ideology that he called "hegemony": false beliefs that are not imposed on the exploited-whether through false consciousness or coercion-but consciously accepted by them (Gramsci 1992b: 201, 219). According to Gramsci, hegemony is freely assented to because doing so proves advantageous; it allows a person to behave according to the parameters of dominant ideology, and, therefore, to do as the majority does, to fit into society. Hegemony is thus experienced by the oppressed as the best course of action, an expression of "common sense" (Gramsci 1992a: 173): indeed it informs one's practices, giving meaning to life in a concrete way and offering guidance on how to behave with good sense at home or at work. Hence we have, with Gramsci, a variation on the original Marxist premises. Hegemony, is not, as in Marx's ideology, something we think, but something we do: a practice that, although not based on truth, is not, strictly speaking, false because it resonates with one's real experiences (Eagleton 1991: 118).

Humans, for Gramsci, always navigate the world according to interpretations of reality that make sense to them in light of their experiences: descriptions of the real-ideologies - that make them conscious of themselves as subjects who act in the world. And while it is true that the dominant ideology is based on false premises, it is also true that some ideologies might have an emancipatory quality, an inherent capacity to provide awareness that one is a subject capable of action. In Gramsci's view, therefore, the difference between good and bad ideologies does not reside, as Marx has it, in how truthfully they represent reality, but in how good they are at situating us in the world (Gramsci 1992b: 175). Based on experience, the dominant ideology contains both elements of conformity ("in my experience doing as others do proved good for me") and potential resistance ("that one time I did not do as others do it was good for me") (Eagleton 1991: 118). Consequently, it produces a sense of being in the world that is marked by contradictions. Bearing this in mind, Gramsci believed that revolution should not try, as Marx argued, to end ideology; rather, it should establish a better ideology that accounts for our experiences in a coherent, noncontradictory manner (Williams 1977: 111).

Gramsci's thought expresses the inevitability of ideology. In his analysis there is the sense that humans never see reality as it is, but always through the medium of 
ideological interpretations, a notion that we find in the majority of modern Marxist investigations, and particularly in the work of leading Hungarian philosopher Georg Lukács. Much like Gramsci, Lukács argued that it is impossible for us to perceive the real without ideology; however, he took this notion in a slightly different direction. He believed that even though we cannot see reality fully, we can still grasp parts of it-glimpses of the truth, so to speak-and this, for Lukács, is precisely the problem with ideology. For Lukács, ideological narratives interpret the world on the basis of partial understandings (1971: 204), so that, rather than lies, they are better described as partial truths. ${ }^{6}$ Like Gramsci, however, Lukács did not believe that all ideologies are equal. While all offer an incomplete understanding of reality, some are more incomplete than others (Eagleton 1991: 98). That is the case, in Lukács's view, with the ideology of the dominant classes, which certainly has something to say about who is supposed to dominate and to be dominated in society, but fails to elaborate-indeed, is practically silent-on the underlying reasons that might determine the exploitative relationship between the two.

Other ideologies, Lukács argues, offer a more detailed interpretation of the world, and if Marxism itself might be considered an ideology, Lukács believes that it belongs to this second type: it searches for deep connections between things; it tries to put together a bigger picture that accounts for complexity (Eagleton 1991: 96). In short, it is a partial truth that is less partial than others. Such considerations have brought Marxist thinkers to argue that the opposite of ideology, or at least of bad ideologies, is neither truth nor reality, but complexity. Ideology does not so much misrepresent the real but selects certain aspects of reality, which may even be true, and presents them as the whole: a reflection that has pushed a number of Marxists to draw a parallel with psychoanalysis. As famously argued by Sigmund Freud, our relationship with the unconscious is one of selection. Our mind selects our memories and perceptions, and it represses the more complex and disturbing-often, perhaps, the truer ones-by relegating them to the unconscious, so that our conscious identity is, in actual fact, a simplified version of ourselves. Similarly, ideology removes complexity from the world and from the self, producing a reductive, sanitized, simplistic sense of identity and reality. ${ }^{7}$

Among those who tried to complement Marx's theories with Freud's insights, German theorist Theodor Adorno deserves special mention. Adorno argued that,

6. Lukács explains this partiality by arguing that thought is a component of any process of change (1971). The moment an oppressed group thinks about its conditions, the concrete possibility of resisting oppression appears: thought immediately becomes part of a change in reality. According to Lukács, therefore, we never know reality fully because the very act of knowing - of thinking about realitychanges it (Eagleton 1991: 94). For a Marxist critique of Lukács see Poulantzas 1987.

7. Some Marxists have preferred an analogy with language. Jürgen Habermas, for instance, sees ideology as a form of communication that has been distorted to such a degree that it has lost both the criteria according to which it can be judged to be distorted and the linguistic tools that allow us to describe it as such (1984: 39 ). 
as ideology abhors complexity, it creates anxiety about anything that is difficult to grasp because it is different from us (Adorno 1973: 161; Eagleton 1991: 126), encouraging an obsession with sameness (Jameson 1981: 114-15) and the formation of a self that knows no other. The role of revolution, for Adorno, is therefore that of rediscovering otherness and heterogeneity in order to "open the road to the multiplicity of different things" (Adorno 1973: 6) that exist outside of ourselves and that are not accounted for by ideology. ${ }^{8}$ In a unexpected twist, Marxists like Lukács and Adorno thus turned Marx's interest for "reality as it actually is" on its head by showing that ideology focuses precisely on the way a given thing is, and hides the links that connect things with each other: the fact that "what is, is more than it is" (Adorno 1973: 161). If Gramsci endorsed the creation of a coherent way to look at the world, with Adorno we almost see a suspicion of anything that is too coherent, because any easy-to-grasp, one-dimensional view of the world bears, potentially, the mark of oversimplification and ideology (Marcuse 1991: 13).

Some Marxists took this approach to its logical extreme. French philosopher Louis Althusser, for instance, argued that the very idea of a coherent self-the sense of identity that allows us to say "I"-is the product of ideology. If it is true, as psychoanalysis holds, that for the conscious self to emerge, the most complex aspects of the self have to be repressed in the unconscious, then, Althusser argued, the "I" is the result of ideological simplification: a product of the repression of our own multiplicity (Althusser 2001: 109). As we have explained in chapter 3 , this operation is achieved through what Althusser calls "interpellation." The moment that someone, particularly someone in authority like a teacher, parent or policemen, addresses us as "you," our ideological "I" is born, and we immediately interiorize the place of subordination that the dominant ideology has assigned to us in society, such as that of a student, child, or citizen (109). ${ }^{9}$ In proposing these arguments Althusser was influenced by Jacques Lacan, a psychoanalyst whose ideas have permeated the most recent discussions of ideology, particularly the work of Slavoj Žižek, a Slovenian philosopher whose thought measures how far Marxist thinkers of today have moved away from Marx's original formulation of ideology as unreal lie.

Žižek borrows from Lacan the idea that one should differentiate between the Real — the truth of the world and of our selves—and Reality — the truth as we experience it and try to make sense of it (Žižek 1995: 14). Using this differentiation,

8. Adorno also warns us against the opposite extreme. Focusing merely on difference is also an ideological move, because to identify what is singular one has first to assume a sameness against which the singular can be defined as such. For Adorno, therefore, "singularity is itself an abstraction, the waste-product of identity thinking" (Dews 1994: 57).

9. Althusser also believed that ideology becomes so interiorized by the subject that it mainly works at the level of the unconscious (Eagleton 1991:115). For a Marxist critique of his approach see Hall 1985; Eagleton 1991: 144; Thompson 1995. 
Žižek argues that we never see the Real because facing it would overwhelm us to the point of psychosis. Rather, we always try to render it comprehensible by using our interpretations, our ideologies. Even though ideology is a fiction, a discourse that never faithfully represents the Real, without it we could not have a livable reality (Žižek 1994, 2008: 45). Contrary to Marx, Žižek thus maintains that the Real, or actual truth, has to stay hidden behind ideology for reality, our truth, to emerge. Žižek clarifies, however, that in our lives we always have experiences that contradict ideological explanations of the world, phenomena that remind us that ideology cannot account for the whole of the Real. ${ }^{10}$ For revolution to happen, Žižek holds, we should not try to create more coherent or more complex ideologies that account for these contradictions, as per Gramsci and Lukács; rather, we should capitalize on this very capacity of the Real to resist being encompassed by ideology, as it can help to subvert dominant discourses. ${ }^{11}$ Yet in doing so, we should also always remember that, ultimately, revolution, like every human endeavor, is an ideological construction. Given that for our reality to exist we necessarily need to act as if ideology is the truth, revolution too should be pursued by believing it is the truth. Then, should the revolution succeed, we should retroactively treat it as a "real truth" that has been such all along (Žižek 2009: 460).

\section{BELIEVING AND PRETENDING}

These intellectuals have proposed different approaches to ideology. In broad terms, however, one can identify three main issues that seem to be at stake in the Marxist analysis: the fact that people experience and believe in ideology as the truth; the role of ideology as the medium through which we see reality; and the question of whether revolution can establish a better ideology, a less partial, more comprehensive worldview. Let us therefore shift the discussion and consider how these three issues play out in actual revolutionary contexts, first briefly elaborating on Žižek's analysis, particularly in relation to how power-holders disseminate propaganda-false ideological information-for political purposes. Expounding on his idea that truth needs to be hidden by ideology for reality to take place, Žižek argues that, deep inside, citizens know the truth about propaganda; they know it is false (2008: 74-75). However, they behave as if they do not, because the truth, the fact that power-holders lie to them, is destabilizing. Therefore, they repress their knowledge of the truth, so that their everyday reality can persist; they ignore the

10. In the early work of Lacan, the Real indicates primordial pre-language experiences we feel in our body and mind, but later on Lacan uses the term to indicate the fact that language and ideology always fail to make sense of everything we experience. In this sense, the Real is not an actual thing but the very limitation of culture and language: a gap (Žižek 2008: 191-95).

11. For an explanation of how the Real's resistance toward Ideology can also sustain Ideology, see Žižek 2008: 140-43. 
fact that they have been given a false interpretation of things so that they can go on with their work, lives, and routines. Žižek argues that people begin by pretending propaganda is true, and then this becomes such an important part of their world that they end up believing that it is (74-75), a consideration that can help us tackle the first of our three issues, people's belief in ideology.

Ethnographic accounts have problematized Žižek's analysis. Take, for instance, Yael Navaro-Yashin's analysis of Turkey, a country whose political discourses have been marked by the so-called Atatürk Dervimleri, a series of revolutionary reforms introduced by Mustapha Kemal Atatürk, the founder of the modern Turkish state. In the 1920s Atatürk introduced radical changes in the country, dismantling various state practices rooted in Islamic discourses that had operated during the Ottoman Empire, thus supposedly turning Turkey into a secular state. NavaroYashin shows that the Turkish state still relies on motifs from Atatürk's revolution to create propaganda aimed at legitimizing itself. ${ }^{12}$ In analyzing this state of affairs, she explains that often Turkish citizens pretend to believe in state ideology. More specifically, she shows that, while it is true, as argued by Žižek, that sometimes, by pretending, these subjects start to believe, it is also true that often they simply pretend in order not to be bothered by the Turkish government (Navaro-Yashin 2002: 1-16, 162-71, 179). Such considerations help us detect an aspect of ideology that seems to have escaped the gaze of Marxist intellectuals-namely, that while it is true that ideology can permeate our identity and our world, it is also true that when it comes to the lies of power, there is space for pretense. Publicly portraying oneself as a believer in an ideology while privately remaining skeptical of it remains an option, a phenomenon that has also been documented in other ethnographic contexts where resistance has been shown to take place "offstage" through implicit and subtle strategies (Scott 1985: 241-89, 1990; Weeden 1999: 67-86).

It is also important to stress that, at times, tracing a clear-cut difference between pretense and actual belief in ideology-a distinction that seems to be implied in the theories of the Marxist philosophers we have mentioned-proves a difficult task. Although Žižek proposed that the former always paves the way for the latter, often the two seem to coexist. This was the case, for instance, in Libya, before the popular revolution of 2011-aided by a controversial military intervention by the international community-put the socialist rule of Colonel Muammar Gaddafi to an end. As part of his propaganda machine, Gaddafi had filled Libya with giant photographs of himself on billboards that portrayed him not only as a symbol of the nation, as per his motto "Gaddafi is Libya, and Libya is Gaddafi", but also as an undefeatable fighter and prophetic guide: a being with supernatural status not achievable by commoners (Khatib 2013: 185). When the anti-Gaddafi revolution

12. Navaro-Yashin (2002) problematizes the difference between secular and religious, showing how in Turkey they are both expressions of the same culture of statism. 
took place, however, Libyans reversed this ideological project (187). They drew mocking caricatures of Gaddafi on walls and buildings, transforming the leader from a semi-divine being into an object of derision: a transmutation that culminated in the colonel's brutal death (197). ${ }^{13}$ When the revolutionaries captured Gaddafi, they ridiculed him and killed him, thus marking the end of a process in which Libyans had seemingly gone from believing in propaganda to rebelling against it. A closer look, however, discloses that, under Gaddafi, people's attitude toward his ideology was not one of full acceptance, as one might expect following both Marx and Žižek, but an indistinguishable blend of sincere credence and genuine skepticism.

Undoubtedly, Libyans were not immune to Gaddafi's ideology, and at times they even embraced it by putting up portraits of the superhuman leader in their workplaces. However, they also referred to Gaddafi in extremely human terms. Often they called him "Muammar," using his first name, so that in the event of being questioned by Gaddafi's police over negative comments, they could say they were talking about a different Muammar, quite a common name in the country (Cherstich 2014b: 102). This was certainly a precautionary measure, but it was also a way to stress the mere humanity of the leader, a trait that was underlined by using fleshly insults when referring to Gaddafi, swearwords that were commonly deployed in everyday life: kelb (dog), tes (goat), zamil (effeminate homosexual) (102). Libyans thus pretended to believe in the ideological framing of Gaddafi as superhuman while in fact they knew he was just a man. ${ }^{14}$ What is interesting to notice, however, is that the same people who described Gaddafi as a cunning politician who fooled his people through propaganda also admitted that there was something uncanny about him, as demonstrated by the fact that he had remained in power despite numerous assassination attempts (102).

Although Libyans did not buy into the propagandistic view of Colonel Gaddafi as a supernatural benign force, they did accept the possibility that their leader might have some magical traits, describing him as a scary, eerie entity. Often they alternated between calling him some colorful swearword and referring to him as "Shaytan" (Satan). For some, Gaddafi was a sorcerer, an expert in manipulating genies that would tell him in advance of any threat or plot against him (Cherstich 2014b: 103). For others, Gaddafi had mastered the dark arts to such a degree that he had been able to transcend the limits of human nature; often people even questioned whether the leader was mortal at all (104). One might therefore assume

13. On the role of aesthetics and representation in recent revolutionary contexts see Werbner et al. 2014, and Winegar 2016.

14. Arguably the only one who fully believed in Gaddafi's propaganda was Gaddafi himself. According to Abercrombie et al. ([1980] 2014: 2), dominant ideologies ultimately succeed in establishing certain views of the world because they are passionately believed in by the dominant rather than by the dominated. 
that Libyans were entangled between pretense and belief, although the element of belief played out differently than Gaddafi had expected. The views of Gaddafi as human and superhuman thus coexisted, and it was only with the revolution of 2011 that Libyans were able to actualize one of the two possibilities. In producing caricatures of their leader, images that, by exaggerating his facial traits, stressed his corporality, Libyans were finally able to establish Gaddafi's humanness, a trait established once and for all with his killing (94).

This brings to mind the notions discussed above, particularly Gramsci's understanding of ideology as discourse marked by contradictions-in this case the contradictory view of Gaddafi as both mortal man and magical entity-as well as the view of revolution as an occasion to embrace a noncontradictory view of the world, demonstrated by Libyans who choose to see their leader as merely a man. It is important to remember, however, that often people do not seek to solve the contradictions of ideology, nor they do feel forced to choose between pretense and belief. Rather, at times, ideology does not demand belief to begin with. A similar dynamic is documented in Alexei Yurchak's analysis of the USSR between the 1950 s and the 1980s. In unpacking this scenario Yurchak argues that in late socialism, state ideology was much more concerned with form, with people behaving in ways that formally reinforced the ideology, than with content, that is, sincere belief in the socialist doctrine (Yurchak 2006: 25). In local elections, for instance, Soviet citizens would vote without bothering to discover the implications of their vote, and the state had no interest in cultivating a more committed attitude toward these political duties (25).

Significantly, Yurchak explains that people did not perform these acts because they feared repercussions from the government. Rather they did so because late Soviet ideology was performative and flexible in nature (27-28). Ideological discourses allowed people to attach their own meanings to the performance of their duties as Soviet citizens, which, although often dissimilar from those of official state ideology, were not perceived by the government as a form of resistance, nor did they prevent subjects from feeling a genuine affinity toward socialism (27-28). Yurchak's study, therefore, invites us to unpack the difference between belief and pretense, putting forward the notion that ideology may have more to do with behavior, performativity, and personal reinterpretations than with static belief or codified experiences.

This is a consideration that, incidentally, resonates with the findings of the vast anthropological debate on the notion of belief (e.g., Needham 1972; Asad 1983; Latour 2010), and with the works of anthropologists and sociologists who have shown that individuals do not necessarily perceive the contradictory aspects of ideological narratives as incongruous (e.g., Asad 1979; Hall 1980; Ortner 2006; Schielke 2009). Interestingly, however, Yurchak's study also presents ideology as that which stands between people and their reality. Though fluid and prone to 
different interpretations, Soviet state discourse was a medium that allowed subjects to make sense of their actions, a point which leads us to assess the second major issue we identified in the debate on ideology: the way in which ideological discourses mediate people's relations with the world and with themselves.

\section{THE GREAT MEDIATOR}

As we have seen, thinkers like Gramsci and Lukács concede that human beings always see the world through the lens of their ideological interpretations. According to these philosophers, therefore, our experience of things is never immediate; rather, it is necessarily mediated by ideology. Nonetheless, as we have also seen, Marxist theorists, with the noticeable exception of Žižek, also articulate revolution as offering the possibility to lessen the mediating capacity of ideology to such a degree that the complexity of reality - the real as it is-becomes more visible. Marxism thus seems to imply, at least in some of its incarnations, not so much an attempt to completely do away with that which mediates between ourselves and reality but, rather, the desire to reduce it to the minimum necessary: a theme that can be seen in many aspects of Marxist praxis. Take, for instance, Lenin's understanding of the "withering away of the state" mentioned in chapter 2. This notion encapsulates the idea that, although under communism people are supposed to rule themselves without a state, they cannot do so straight away. The role of the state as mediator between the masses and the exercise of power is still deemed necessary in the first phases of revolution. While eventually the state must disappear, this process is seen as one of slowly fading away, a reduction to the minimum necessary: a view that differentiates Marxism from other revolutionary epistemes like anarchism which, as we have seen, advocate either the instant eradication of all mediators (be it the state or other institutions) (Chomsky 2008: 94-95; Lenin [1917] 2014: 97), or the immediate creation of spaces that operate autonomously from these mediators (Graeber 2002: 68).

It is important to stress, however, that not all revolutionary discourses are concerned with reducing the mediation of ideology and unveiling reality as much as possible. In fact, some revolutionary theories aim at doing the very opposite: augmenting the degree of mediation. Consider the case of Iran. Even though different sections of Iranian society, including Marxist associations and religious groups, contributed to deposing the Shah, eventually, as we have seen in chapter 3, senior cleric Ruhollah Khomeini prevailed as leader of the revolution. Doubtless, Ayatollah Khomeini appropriated bits of Marxist language, mainly in matters of popular mobilization, and, like Marx, understood revolution as enabling people to access the true reality of things (Varzi 2006: 36-37). However, the leader also acted as an intermediary between Iranians and divine will: the interpreter of those pieces of Islamic jurisprudence that, in his view, justified his revolutionary actions and poli- 
cies. Indeed, Khomeini's mediating power was so effective that his public speeches would come to have binding legal value as soon as they were spoken (36-37). In sharp contrast with the Marxist approach, the Iranian leader thus presented himself as a necessary medium through which the truth could be shown to the masses: a notion that Khomeini articulated in complex spiritual terms.

Using themes from Iranian Sufi mysticism and drawing on esoteric interpretations of Shi'a cosmology, Khomeini referred in his speeches to the Sufi distinction between baten (the inner, true nature of reality) and zaher (the outer, external, and superficial facet of the real: a "veil" that covers up the truth) (Mottahedeh 2000; Varzi 2006: 5, 19). In Iranian mystical doctrines, one can never completely uncover the inner reality and directly face it, as this dimension is too intricate and deep to be grasped. Rather, the truth can only be understood through the medium of the outer, that is, through allegories, symbols, and veiled poetic descriptions that reveal some aspects of the truth and, at the same time, conceal others (Varzi 2006: 4). Now, Khomeini presented himself as the one who could guide Iranians through this complex maze of metaphors and indirect references. Furthermore, he articulated his very persona as a metaphor. Even though he emphasized that people should exercise power in a direct and unmediated fashion-an approach that led him, among other things, to launch a referendum that allowed Iranians to choose between the Shah and his own rule-he aimed at presenting his image as the key allegory through which one could understand the revolutionary process and participate in it.

To this end, photographs of Khomeini were mass-produced and used as the lens through which one could contemplate the spiritual aspects of the revolution (Varzi 2006: 6, 27). The pictures were pinned to the uniforms of Iranian soldiers and even, in some cases, to the graves of the dead, meaning that Khomeini was present on the battlefields, at mourning ceremonies, everywhere; seeing Khomeini's likeness people could identify with him and interiorize his teachings $(6,27)$. This practice resonated with Iranian Sufi doctrines according to which religious images are useful tools that can help one contemplate divine truth: media that allow the Sufi to slowly grasp the mystical reality that lies beyond the image and ultimately within oneself (28-30). Such use of spiritual motifs illuminates the deeper aspects of Khomeini's thought, and helps us to shed light on the difference between the Marxist view of revolution as an occasion to lessen ideological mediation and the Iranian one as an amplification of it. Nonetheless, there is an important clarification to be made. Since the Iranian Islamic state sprang out of a Shi'a setting, where clerics often act as intermediaries between people and divine will, one might conclude that it is precisely because of Shi'a cosmology that Khomeini emphasized the concept of mediation, whereas Marxists, being adverse to religion, tend to reduce it. This, however, would be a great simplification of the revolutionary dynamics that are at stake here. 
Doubtless, some Shi'a discourses put great emphasis on the notion that truth needs to be mediated: an aspect that particularly stands out if one compares, for instance, Shi'a Islam with Sunni Islamic traditions where mediation, though present, has less prominence. ${ }^{15}$ Nonetheless, the situation is more complex, and mediation cannot be seen as the inherent trademark of Shi'ism-as opposed to Sunnism - as shown by a brief comparison with Gaddafi's case. In his writings, the Libyan leader often combined Sunni discourses, socialist doctrine, and antiShi'a criticism to stress that people should exercise power without mediators, a recurrent theme in Gaddafi's revolutionary theory used in order to portray himself as a champion of Sunni orthodoxy (Gaddafi [1975-81] 2005). However, as we have seen both in this chapter and in the previous one, Gaddafi, too, acted as a mediator. Like Khomeini, he also used imagery aimed at presenting himself as an embodiment of the nation: not so much a representative of the Libyans but rather a medium standing between them and the realm of politics. These considerations give us the chance to clarify an important point: although Khomeini's and Gaddafi's revolutions were cosmological events (an aspect that will be explored in greater detail in the following chapter), they were not static expressions of local cosmologies. Rather they were projects that emphasized some aspects of the Shi'a and the Sunni repertoires and downplayed others. It is by looking at the tendency to select aspects of established religious traditions that we can better compare these revolutionary instances with the Marxist episteme.

Even though, as we have seen, Marxist philosophers like Lukács identified in ideology a tendency to select some parts and present them as the whole, this very propensity can be found in the Marxist tradition as well. While such a realization does not prevent us from answering the Marxist invitation to identify the selective descriptions of reality that power puts forward for its murky ends, one cannot help but notice that Marxism, too, has taken up some aspects of religious discourses and omitted others. While Marx excluded God from his worldview, he kept, one might say, a spiritual sensibility. In describing the dehumanizing nature of capitalist society, he spoke of a system that is de-sanctified (Berman 2010: 115), a sad condition where "all that is holy is profaned" (Marx and Engels [1848] 2005: 10). One can also detect a similar attitude in contemporary Marxist works, some of which will be further explored in the concluding chapter of the book, where themes of the Christian tradition are reinterpreted and used as metaphors that help to elucidate new interpretations of Marxist doctrine (Badiou 1997; Žižek 2003). At times these analyses even defend what they see as the positive aspects of religion against the attacks of liberal atheists (Eagleton 2009), an approach rooted in Marx's view

15. These, of course, are not static features of the two main Islamic traditions. Arguably the fact that religious scholars have lost their authority in the Sunni world is mainly a modern phenomenon (Eickelman and Piscatori 1996: 46-68). 
that, although religion is a lie, it is often also the "sigh of the oppressed creature" (Marx 1970: 131), a way to voice the heartfelt laments of the poor against the injustices of this world. ${ }^{16}$

These reflections help us identify two important dynamics: first, while it is true that religious revolutionaries borrowed from Marx-from Gaddafi to many other blends of socialism and Islam that have developed in the twentieth century-it is also true that the Marxist tradition borrowed from religion. ${ }^{17} \mathrm{Sec}-$ ondly, leaving aside old-fashioned and simplistic discussions of whether Marxism is better understood as a secular religion, a position held by many detractors of Marxist philosophy, one cannot help but notice an unequivocal resemblance between Marx and the monotheistic traditions. This is a likeness that has long been observed by scholars (Löwith 1949: 33-51) and at times even acknowledged by Marxists themselves, to the point that some have identified an inherently theological kernel within Marxism (Benjamin 2002: 288-91, 2007: 253; Weil 2004: 162). ${ }^{18}$ This is particularly true of the Marxist notion that one day, when revolution takes place, ideology will lessen its grip on reality. The Marxist take on ideology implies a Judeo-Christian temporality, a sense of time centered around expectations of things to come (see chapter 1 ), in that it offers the promise of a future earthly kingdom of heaven: a new order of things where there will be very little room for the lies of power, and truth will become more visible than it is today. Bearing this theme in mind, we move on to unpack the last of our three issues: the capacity of revolution to bring about a better ideology, a more truthful way to account for reality.

\section{BECOME WHO YOU ARE}

In order to tackle this final issue, we first need further clarification. The Marxist idea of revolution as the advent of a better ideology should be contextualized

16. Such attitude can be found also in Gramsci, who thought that the oppressed have real spiritual needs, and that Marxism, being a coherent system, could fulfill these needs better than religion (Fulton 1987: 202; Crehan 2002: 118).

17. Although it is often forgotten in public debates, the first modern instances of Islamic revolutions looked at socialism, rather than at a literal interpretation of Islamic scriptures, as a source of inspiration: an attitude inaugurated by Egyptian revolutionary leader Gamal Abd-el Nasser (Nasser 1958). The situation is very different nowadays, and according to some, it is precisely because of the disappearance of a radical left in Islamic countries that Islamism has spread (Žižek 2012: 73-74). It should also be noted that Nasser and Gaddafi, as well as influential Arabic socialist thinkers such as Michel Aflaq (1969), had a complex relationship with orthodox Marxism and disagreed with some of its core tenets.

18. Controversial anarcho-syndicalist Georges Sorel saw the Marxist account of revolution as a myth (2009: 42). Some entirely disagree with this approach, and see the argument that Marxism has a religious genealogy as an attempt to undermine the achievements of modern thought by reducing them to mere secularized versions of religious themes (Blumenberg 1985). 
within a broader Marxist tendency to articulate the present through the lens of the forthcoming. To grasp this inclination one can consider, among other things, the way Marxism sees the capitalist system. For Marx, exploitation will disappear with the advent of revolution; thus, capitalism is a source of suffering that will one day pass. Interestingly, however, capitalism is also a suffering that, once contextualized with an eye to the future, has a redemptive side. Since, as we have seen, capitalism entails a contradiction-its reality disproves its ideology-Marx sees in it an occasion to acknowledge the wrongs of today and to take the first step toward the establishment of a better tomorrow, so that revolution appears to be, in a sense, the historical, inevitable product of the contradictions of capitalism (Berman 2010: 104). Capitalism is therefore, to some extent, a necessary evil, reminding us of the "felix culpa," or "happy fault," of the Christian tradition, the idea that even the original sin committed by Adam has a redemptive side since it is precisely because of it that Christ came to redeem the world. The lies of capitalism, like the lies of the serpent in the Garden of Eden, thus have a role to play in the trajectory that leads to the establishment of the truth, a perspective that has generated descriptions of Marxism as a secular "theodicy," a "justification of God," an apologetic discourse typical of Christian theology's search to decipher the part played by evil in the process of mankind's salvation (Eagleton 2010: 136). ${ }^{19}$

Marxism's promise of a better ideology is, therefore, founded on the idea that, in the words of Marxist thinker Ernst Bloch, "the world without future-laden properties does not deserve a glance" (1995: 223): the notion that "our best days have yet to be lived," to quote Turkish communist poet Nâzım Hikmet (2002: 86). Interestingly, such need to make sense of the present only in light of the future has been documented also in a number of non-Marxist revolutionary contexts. Take, for example, Samuli Schielke's account of the 2011 Egyptian revolution. Schielke argues that this uprising was an impulsive event without a specific agenda. Nevertheless, he also shows how Egyptian revolutionaries chose to interpret it as a process of change: a precise moment in a specific trajectory leading to a different and better future (Schielke 2015: 215). ${ }^{20}$ By reading the uprising in such manner, Schielke argues, revolutionaries developed an "ethos of futurity" (215), a sense that life should be lived through a constant search for the new and better (see also

19. Marx's certitude in the advent of revolution is instilled with a sense of providence, a trait that he inherited from his chief philosophical inspirer, Hegel. Marx's faith is such that he welcomes the full flourishing of capitalism as the necessary prelude to revolution (Carandini 2005: 3). For an anthropological—and socialist—critique of this view see Robinson 2019.

20. Such notion that revolutionary discourses can be radically altered in the course of revolutionary action is found in a number of analyses of the Arab Spring. For instance, Kjetil Fosshagen (2014) has argued that the popular revolutionary spirit of the recent uprisings that have occurred in North Africa has been hijacked by the local liberal upper-middle classes. Fosshagen draws a parallel with the Spring of Nations - the wave of upheavals that took place in Europe in 1848-where a similar dynamic took place. The parallel has been proposed also by Alain Badiou (2012). 
Mittermaier 2019: 155-78). As we have explained in the introduction, in Schielke's view, this "ethos of futurity" was rooted in two discourses: capitalism, with its insatiable search for new ways to achieve profit; and literalist Islam, with its focus on the rewards that the faithful will one day enjoy in the afterlife (Schielke 2015: 105, 122). However, bearing in mind what we have said, and notwithstanding Schielke's shrewd insights, one wonders whether the Egyptian case actually echoes, at least in some ways, the Marxist model. Certainly, it bears a similarity that, to be properly assessed, demands a brief critical examination of Schielke's analysis, particularly in relation to the way in which, according to Schielke, Egyptian revolutionaries articulate the present.

Schielke (2015) documents the dissatisfaction with the "now" attendant on the future-oriented ethos of Egyptian revolutionaries, an attitude that, in his view, mirrors capitalism's tendency to dismiss the present in favor of novelty and Islamism's demands for religious perfection that are often met with failure and imperfection in the "here" and "now," but that will propel the faithful toward a better future in heaven. However, like the Egyptians, Marx too was frustrated with the present, likewise seeing it as a time that "gives no satisfaction" (Marx 1993: 426). Although he detected an obsession with newness in capitalism, a tendency for things to "become obsolete before they can ossify" (Marx and Engels [1848] 2005: 10), he, too, could not help but include the present in a future trajectory. Therefore, there is a difference between Marxism and the Egyptian revolutionary ethos on one side, and Islamism and capitalism on the other, and this difference does not lie in their orientation - which in both cases points toward the future-but in how they conceptualize this future. Capitalism and Islamism look at the forthcoming with a sense of permanence. The tomorrow they promise relies on the idea that the free market, or the literal interpretation of Islam, will stay unchanged for all eternity, and that future newness will take place only within these unchangeable premises (Graeber 2011: 32). Conversely, Marx, and arguably the Egyptian revolutionaries, see the future as impermanent; they conceive of the possibility of a completely new, radically different point of view on things awaiting us in the future: a fundamental change in ideology, to use the Marxist language.

Perhaps this similarity between the Marxist model and the Egyptian case (their shared understanding of the future) becomes more visible when one compares them with revolutionary instances that are not based on the notion of a future horizon of change (e.g., see Haugbolle and Bandak 2017). Take, for instance, Ross Porter's study of the Yemeni revolution of 2011. ${ }^{21}$ Porter shows how Yemeni revolutionaries, although concerned with changing the dictatorial policies of President Ali Abdullah Saleh, did not articulate such change in terms of future developments that would one day replace the current state of affairs. On the contrary, they saw change as some-

21. On previous revolutionary insurgencies in Yemen, see Vom Bruck 2005, 2019. 
thing to be experienced in the moment: the realization, made in day-to-day life, that one can be immune to the oppressive ways of thinking and behaving pervasive under Saleh (Porter 2016: 64, 2017). According to Porter, the Yemeni revolution was therefore not so much focused on expectations of a better tomorrow where things would be clearer, truer, or better; rather, it involved a sense of hope in the now-the need to experience a better future already in the present-to the point that, in a way, for revolutionaries present and future ceased to be two distinct moments in a chronological trajectory (Porter 2016: 65). In the concluding chapter of the book, we again encounter this idea that revolution might erase the difference between the current and the forthcoming, but for now it suffices to say that the Yemeni case clearly illustrates that some revolutions do not entail the classical Marxist notion that one day, after revolution has succeeded, we will see the world differently.

An even clearer example in this sense is the Bolivian proceso de cambiostrongly influenced, as previously explained, by indigenous practices (Tassi 2017: 1) - in which revolution features not as an ideology-changing operation but as an occasion for Bolivians to free themselves from the need to change, a chance to see the world as they currently see it. While this revolutionary process did not entail a supposedly pure indigenous essence, it did involve an Aymara "subsoil," a substratum of practices and beliefs with inherent continuities and change, cultivated by the Aymara but ignored by Bolivia's white ruling class (Tassi forthcoming, 2016: 1-33). In its inception, the proceso ${ }^{22}$ was framed by indigenous and popular sectors as an instrument helping to bring this subsoil to the surface and taking center stage in the sociopolitical life of the country. This dynamic mirrored the indigenous notion of Pachakuti, or "World Reversal" (Gutiérrez 2014), an important concept in Aymara cosmology that entails the presence of a powerful but hidden underworld where Andean indigenous forms and practices are followed by all, which will one day emerge and prevail, so that even the white will live like "indios." The proceso was therefore a tool for Andeans to crystallize the possibility to be themselves. While the theme of a "return to the true self" is found in many revolutionary discourses - including, as we have seen, Marxism, with its idea that revolution instantiates the true "essence of men"-in Bolivia this notion was articulated without the Marxist stress on the future as a time of radical change. ${ }^{23}$

22. As mentioned earlier, the political project of the state and of indigenous movements have been slowly diverging (see Postero 2017) to the point that the expression "proceso de cambio" is being increasingly associated with the political project of the state.

23. In Iran, for instance, socialist revolutionary thinkers made reference to the notions of "Gharbzadegi" (Westoxification) - the venomous influences of the Colonial West; as a critique against this phenomenon they called on Iranians to return to themselves and to their roots (Al E-Ahmad 1984; Shariati 2015). A similar theme is found in the writings of Mexican poet Octavio Paz, mentioned at the beginning of the chapter, where the capacity of revolution to instantiate a more truthful reality is articulated more in terms of "being who you truly are"-as in, discover who you are already—than in relation to classical Marxist notions of radical change. 
Whereas Marxism carries the monotheistic idea that the truth increasingly reveals itself in history in a redemptive process that reaches its climax when the revolution ameliorates interpretations of reality, the proceso foregrounds the indigenous cosmological theme of the emergence of something that, while neglected, is already present. Although parallels can be drawn here with the Marxist invitation to unveil the reality that lies behind ideology, there is a fundamental difference: with the Aymara there is neither redemption to be sought nor a horizon to be chased. Rather the horizon is already here, and it demands cultivation, not change. Using a familiar Western philosophical language, one might argue that the Bolivian case stands out as one marked by "immanence," as opposed to Marxism which, despite its focus on material conditions, implies "transcendence": the need to transcend the current in expectation of what lies ahead, but also the conviction that, ultimately, reality transcends ideology. Indeed, this is a characteristic of Marxism that, despite numerous re-elaborations, has remained the same since its inception and that marks the difference between the Marxist understanding of revolution and other revolutionary epistemes: the notion that truth lies beyond our descriptions of it and that one must labor to get close to it, with full faith that in the future the distance will shorten.

\section{CONCLUSION}

The different contexts we have cited help us recognize a habit that often features in how ideology is approached by scholars and observers of revolutionary phenomena: a tendency, eloquently documented by Yurchak, to analyze ideology through the lens of static binary oppositions (Yurchak 2006: 5). In this chapter we have problematized some of these dichotomies, namely: the notion that you either believe in ideology or merely pretend to; the distinction between ideological mediation and lack of it; and the idea that the way we see the world now differs from how we will see it in the future. In addition to these three, many further simplistic pairings are implied in those we have considered, which often characterize political commentary, such as the difference between compliance and resistance (5). Our overview shows the limitation of this binary way of thinking; however, one wonders whether the dissolution of dichotomies is the only end result here. Ultimately, rather than simply problematizing the Marxist differentiation between reality and ideology — the greatest binary of all — we have unpacked the way Marxist thinkers themselves have problematized this dichotomy. In short, we have sought to deal with Marxism's complexity, not with its simplicity, and although it is difficult to read all the cases we have mentioned using Marx's conceptual tools, one has to recognize sophistication in the Marxist understanding of the relation between the real and the ideological.

It is also important to stress that, even though dichotomies collapse as soon as we move from one context to another, one detects a common preoccupation in 
all the revolutionary discourses we have analyzed: a concern for what counts as reality and what does not. Doubtless, this preoccupation is not at the heart of all revolutionary experiences, and often the differentiation between real and unreal that marks some revolutionary projects is not as sharp as one might expect; nevertheless, the preoccupation is still there. Therefore one cannot help but notice that revolutions bring with them specific economies of reality and unreality, flexible systems that assign a place to each. There is a distinct way of seeing the world here, although one that is declined in different ways according to different cosmological understandings of what constitutes the real. With this in mind we move to the next chapter, wherein the way in which cosmology informs revolution is further explored. By way of conclusion, however, it is important to clarify that, while unpacking dichotomies can be a way to do justice to some of the cases we have explored, often the most interesting results can be achieved by taking dichotomies seriously: by examining what revolutionary agents understand to be true or false, and how this understanding shapes the world they want to build or preserve, whether it is one marked by the future liberation of the oppressed, or by the emergence of what is already here. Then, should a proposition seem convincing, one might even decide that simplistic binaries do not necessarily prevent us from doing what many revolutionary critiques demand: picking a side. 